\title{
COMPACTNESS FOR THE COMMUTATOR OF THE PARAMETERIZED AREA INTEGRAL IN THE MORREY SPACE
}

\author{
YANPING CHEN AND HONG WANG
}

Abstract. In this paper the authors prove that the commutator $\left[b, \mu_{S}^{\rho}\right]$ is a compact operator in the Morrey space $L^{p, \lambda}\left(\mathbb{R}^{n}\right)$ for $1<p<\infty$ and $0<\lambda<n$, if and only if $b \in V M O\left(\mathbb{R}^{n}\right)$, the $\mathrm{BMO}\left(\mathbb{R}^{n}\right)$-closure of $C_{\mathrm{c}}^{\infty}\left(\mathbb{R}^{n}\right)$, where $\mu_{S}^{\rho}$ denotes the parameterized area integral.

Mathematics subject classification (2010): 42B20, 42B25.

Keywords and phrases: Compactness, commutators, parameterized area integral, VMO, Morrey space.

\section{REFERENCES}

[1] M. S. Berger, Nonlinearity and Functional Ananysis, Academic Press, New York, 1977, 64-107.

[2] Y. Chen And Y. Ding, Compactness Characterization of Commutators for Littlewood-Paley Operators, Kodai Math. J. 32 (2009), 257-324.

[3] Y. Chen, Y. Ding And X. WANG, Compactness for Commutators of Marcinkiewicz Integral in Morrey Spaces, Taiwanese J. Math. 15 (2011), 633-658.

[4] Y. Chen, Y. Ding AND X. WANG, Compactness of commutators for singular integrals on Morrey Spaces, Canad. J. Math. 64 (2012), 257-281.

[5] Y. Chen, Y. Ding And X. WAng, Commutators of Littlewood-Paley Operators on the Generalized Morrey Space, J. Ineq. Appl. Article ID 961502, 20 pages, 2010.

[6] Y. Ding, S. Lu And Q. Xue, Parametrized area integrals on Hardy spaces and weak Hardy spaces, Acta Math. Sinica (English Series), 23 (2007), 1537-1552.

[7] Q. Xue, Y. Ding, Weighted $L^{p}$ boundedness for parameterized Littlewood-Paley operators, Taiwanese J. Math. 11 (2007), no. 4, 1143-1165.

[8] Y. Ding, Q. XUE, Endpoint estimates for commutators of a class of Littlewood-Paley operators, Hokkaido Math. J. 36 (2007), no. 2, 245-282.

[9] T. Mizuhara, Boundedness of some classical operators on generalized Morrey spaces, Harmonic Analysis, ICM-90 Satellite Conf. Proc., S. Igari (ed.), Springer-Verlag, Tokyo, 1991, pp. 183-189.

[10] A. UChiYAmA, On the compactness of operators of Hankel type, Tôhoku Math. J. 30 (1978), 163171.

[11] Q. Xue, Parameterized area integral and Littlewood-Paley operators, PhD Thesis. 2004. 